\title{
Prognostic significance of sex in patients with primary tracheal tumors - a retrospective, single-center study
}

\author{
Aleksandra Piórek, Adam Płużański, Dariusz Mirosław Kowalski, Maciej Krzakowski
}

Lung Cancer and Chest Tumor Department, Maria Sklodowska-Curie National Research Institute of Oncology, Warsaw, Poland

Introduction. We aimed to assess the prognostic significance of the sex of patients with primary tracheal tumors based on our own results as well as the literature review.

Material and methods. We carried out a retrospective analysis of 89 patients with primary tracheal tumors treated at the Maria Sklodowska-Curie National Research Institute of Oncology in Warsaw, Poland, between January 2000 and December 2016. Men and women were compared in terms of overall survival, disease-free survival, and progression-free survival.

Results. In the entire study group, the median overall survival was 61.30 months in women and 8.55 months in men $(p<0.0001) .5$-year overall survival rates were $2.1 \%$ in men versus $50.6 \%$ in women $(p<0.0001)$. Among those receiving radical treatment, women had improved survival rates compared with men. Sex was an independent prognostic factor in both the total study population and among those undergoing radical treatment.

Conclusions. According to our results, women with primary tracheal tumors have significantly better survival than men. Because female sex is an independent prognostic factor in patients with primary tracheal tumors, the ratio of women to men should be taken into consideration in reports comparing the outcomes of different treatments.

Key words: tracheal tumors, adenoid cystic carcinoma of the trachea, squamous cell carcinoma of the trachea, sex

\section{Introduction}

Primary tracheal tumors are rare, and therefore remain poorly understood. They represent $0.2 \%$ of all respiratory cancers and 0.02-0.04\% of all malignancies [1], with an annual incidence of approximately 0.1 per 100000 people. The most common types are squamous cell carcinoma (SCC) and adenoid cystic carcinoma (ACC), which together account for more than two-thirds of primary tracheal tumors in adults [2].

Squamous cell carcinoma of the trachea usually presents as multiple and often ulcerative lesions growing into the tracheal lumen, with histology identical to that of SCC of the lung [3]. Squamous cell carcinoma can occupy any part of the trachea, and a third of patients have mediastinal or pulmonary metastases at diagnosis [2]. Of the trachea is 2-4 times more common in men than in women and develops primarily in the sixth and seventh decades of life [2-5]. It is strongly associated with tobacco smoking $[3,4]$, and $30-40 \%$ of patients with SCC of the trachea have concurrent metachronous or synchronous primary smoking-related cancer of the oropharynx, larynx, or lung [2,3].

Adenoid cystic carcinoma of the trachea occurs with similar frequency in men and women, and is most common in the fourth and fifth decades of life [2-5]. The etiology of ACC is unknown; however, unlike SCC, it is not associated with tobacco smoking $[3,4,6]$. Adenoid cystic carcinoma is characterized by submucosal and perineural spread [7].

\section{How to cite:}

Piórek A, Płużański A, Kowalski DM, Krzakowski M. Prognostic significance of sex in patients with primary tracheal tumors - a retrospective, single-center study. NOWOTWORY J Oncol 2022; 72: 15-19. 
It often develops slowly, but can be more aggressive in some cases, with a tendency to local infiltration and, less frequently, lymph node metastases. Moreover, local or systemic recurrences may occur beyond 10 years after primary treatment $[2,3]$.

The prognosis of patients with primary tracheal tumors is determined by several factors. Histological diagnosis of ACC $[4,8-20]$, better performance status [14, 16, 21-23], and radical surgery $[4,5,8,16,17,19,24-26]$ have been identified as favorable prognostic factors. Literature on the influence of sex on overall survival (OS) in different tumors has been increasing. An Australian study showed that men had lower 5-year OS than women for all cancers (47.1\% [95\% confidence interval (Cl): 46.9-47.4] versus 52.0\% [95\% Cl: 51.7-52.3]). Specifically, poorer survival for men was observed for 11 cancers (head and neck, esophagus, colon, pancreas, lung, bone, melanoma, mesothelioma, kidney, thyroid, and non-Hodgkin lymphoma) [27]. Several studies on the most common respiratory cancer - non-small cell lung cancer - have shown that women have a lower risk of disease progression and death than men [28-31]. Better prognosis for women with lung cancer has also been shown in Polish studies [32, 33]. In an American study based on the Surveillance, Epidemiology, and End Results (SEER) database, women with ACC of the head and neck had better OS than men in multivariate analyses (HR 0.73; 95\% Cl: 0.65-0.82) [34]. Data on the influence of sex on the survival of patients with primary tracheal tumors are lacking. In this study we therefore aimed to examine the prognostic significance of sex in patients with primary tracheal tumor.

\section{Material and methods}

This retrospective analysis included patients with primary tracheal tumors treated at the Maria Sklodowska-Curie National Research Institute of Oncology in Warsaw, Poland, between January 2000 and December 2016. Patients were identified by searching the institution's cancer registry. We enrolled adults ( $\geq 18$ years) diagnosed with primary tracheal tumors for whom complete data were available. Patients with tumors that may have originated from the larynx, main bronchus, or other organs (e.g., thyroid or esophagus) were excluded.

Overall, the records of 89 actively treated patients with primary tracheal tumors were included. Data on demographics, clinicopathological variables (symptoms, smoking history, performance status, histological diagnosis, location, and extent of the tumor), and type of treatment were extracted from traditional (paper-based) and electronic medical records. The follow-up ended on December 31, 2019.

Differences in distribution were determined using one-way analysis of variance for normally distributed variables and the Kruskal-Wallis test for other continuous variables. Fisher's exact test was applied to assess the independence between categorical variables.
The Kaplan-Meier estimator, log-rank test, and Cox proportional hazards model were used to analyze survival. For all tests, statistical significance was set at $p<0.05$. Variables for which the $p$ value was less than 0.10 were included in the multivariate Cox models.

OS was defined as time from diagnosis to death from any cause. Disease-free survival (DFS) was defined as time from initiation of radical treatment to recurrence or death from any cause, and progression-free survival (PFS) as time from initiation of palliative treatment to disease progression or death.

\section{Results}

\section{Clinicopathological characteristics}

Among the total study population $(n=89)$, men slightly predominated (48 men and 41 women). The median age at diagnosis was 62 years. SCC was the most common histological type, identified in 50 (56.2\%) of 89 patients. 19 patients were diagnosed with ACC (21.3\%). The remaining histological findings were classified for statistical purposes as "other". Men were more frequently diagnosed with SCC (66\%), whereas ACC predominated among women (73.7\%). The majority (78\%) of patients with SCC were over 60 years of age and none were under 35 years of age. ACC was diagnosed in all age groups (36.8\% of patients were under 35 years of age). Among the 43 patients for whom data on smoking history were available, $100 \%$ of those diagnosed with SCC were current or former smokers. Only women were never-smokers. The most commonly reported symptoms were dyspnea (37.1\%) and hemoptysis (36\%). $68 \%$ of women and $56 \%$ of men had a WHO performance status of $0-1$. Among the patients who underwent radical treatment, 28 (62.2\%) were women and 17 (37.8\%) were men, compared with 13 (29.5\%) women and 31 (70.5\%) men among those receiving palliative treatment. 13 (28.9\%) of 45 patients receiving radical treatment underwent surgical resection, of whom 11 (85\%) were women and two (15\%) were men.

\section{Survival analyses}

For the entire study group, the median OS was 61.30 months in women and 8.55 months in men $(p<0.0001)$. 5-year OS rates were also significantly higher in women than in men $(50.6 \%$ vs. 2.1\%) (fig. 1). Among those who underwent radical treatment, 5-year OS rates were 5.9\% in men, compared with $70.6 \%$ in women ( $p<0.0001)$. Median OS in this group was 16.9 months in men versus 129.4 months in women ( $p<0.0001$ ) (fig. 2). 5 -year DFS rates were $10.9 \%$ in men versus $33.6 \%$ in women $(p=0.0023)$. Sex was an independent prognostic factor in both the total study population and among those receiving radical treatment. We found no differences in OS and PFS between sexes in patients receiving palliative treatment.

\section{Discussion}

Data on the influence of sex on the survival of patients with tracheal tumors are scarce and inconsistent. In a retrospecti- 


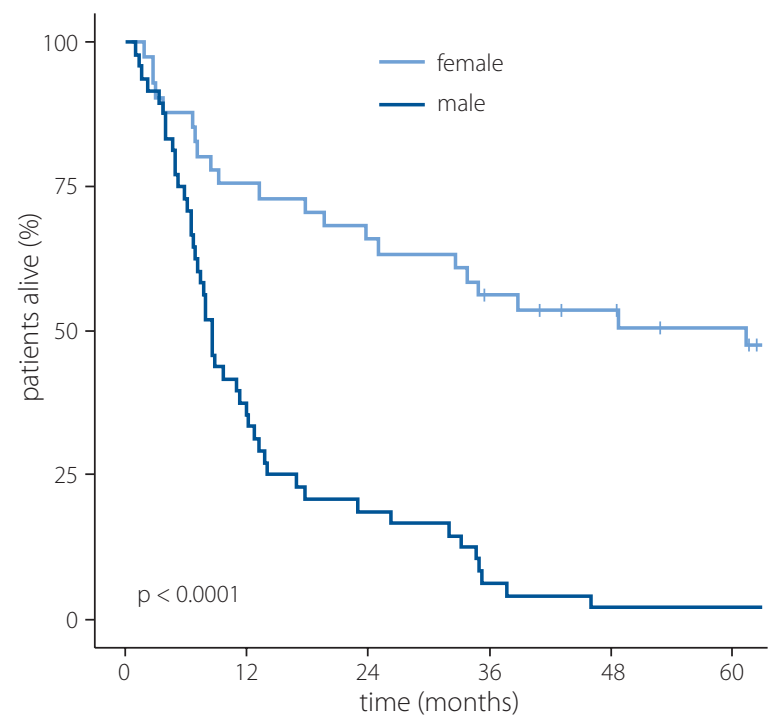

Figure 1. Cumulative probability of overall survival by sex in the total study group

ve analysis of 30 patients with ACC of the trachea, 5 -year OS rates were $92 \%$ in men and $77 \%$ in women $(p=0.345)$ [25]. Moreover, the only available meta-analysis did not identify a statistically significant effect of sex on PFS or OS [5]. Another study showed that women had better disease-specific survival, defined as time from the initiation of treatment to death from the tracheal tumor $(p=0.044)$; however, no effect on OS was identified ( $p=0.467$ ) [10]. In a study of surgically treated patients with ACC of the trachea, female sex was a favorable prognostic factor for DFS, but not for OS [35]. Only one study, by Hetnał et al. [16] reported a favorable OS for women compared with men (5-year OS rates of $7 \%$ in men versus 32\% in women, $p=0.04$ ); however, multivariate analysis did not confirm sex to be an independent prognostic factor.

In our study, female sex was associated with favorable OS. OS and DFS benefits were also seen for women among patients who underwent radical treatment. Sex was an independent prognostic factor in both the overall study population and among those who underwent radical treatment. Various factors were considered to identify the underlying causes of such profound differences in survival by sex.

Analysis of other favorable prognostic factors in men and women showed that, in many cases, women predominated among groups with favorable characteristics. We found that:

- the group of never-smokers consisted of only women,

- the proportion of women and men who had a WHO performance status of $0 / 1, \mathrm{~T} 1$, and N0 were as follows: $68 \%$ vs. $56 \%, 39 \%$ vs. $19 \%$, and $61 \%$ vs. $33 \%$,

- $73.6 \%$ of patients with ACC were women,

- $62 \%$ of women were eligible for radical treatment compared with $38 \%$ of men,

- among those undergoing primary surgical treatment, 11 (85\%) were women and two (15\%) were men.

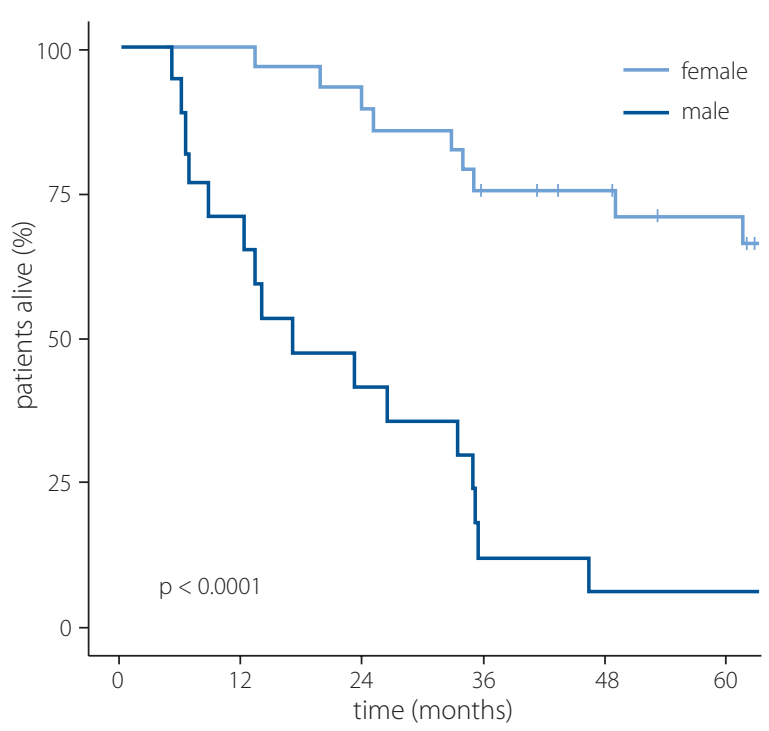

Figure 2. Cumulative probability of overall survival by sex in patients receiving radical treatment

Attention was also paid to the difference between male and female life expectancy. Women live longer than men. According to Statistics Poland, the average life expectancy was 73.8 years for men in 2018, compared to 81.7 years for women. Few studies (and none on tracheal tumors) have taken life expectancy into account. A study on surgically treated patients with non-small cell lung cancer that accounted for expected lifetime found that women had better survival than men [36].

Other factors that may be associated with the above relationship include the patient's age at diagnosis of the tumor and comorbidities. A study in small-cell lung cancer indicated that the relationship between the patient's sex and age was important. A favorable prognostic effect of female sex was observed in younger patients, whereas prognosis in men was independent of age. The median OS in patients under 60 years was 13.3 months for women and 10.1 months for men ( $p=0.0001)$; however, no significant difference between sexes was seen in older patients ( $p=0.12$ ) [37]. Another study also demonstrated improved prognosis in younger individuals (especially among women) [33]. In our study population, 100\% of patients under 35 years of age were women. We found no data in the literature on the correlation between the survival of patients with tracheal tumors and their sex and age.

Sex-specific differences in comorbidities may translate into differences in survival between women and men. Some studies suggest that men have more comorbidities than women at cancer diagnosis and that there is a relationship between comorbidities and poor survival (e.g. in lung cancer) [38]. We did not analyze the presence of comorbidities in our study, nor did we find any data concerning the influence of comorbidities on OS in patients with tracheal tumors in the literature.

Other studies evaluating the effect of female sex on survival highlighted that women seek health care more often 
and sooner than men, which contributes to earlier diagnosis of cancer [39, 40]. Women may also be more likely than men to take the proposed treatment. Furthermore, women more frequently adhere to the treatment plan and better tolerate treatment [34, 41].

Differences in molecular, endocrine, and metabolic abnormalities may be another factor. In other cancers, men and women were found to vary in terms of genetic disorders. For example, the EGFR mutation in non-small cell lung cancer is more common among women than men $[42,43]$. Studies on the aforementioned factors could provide relevant information regarding differences in the biological behavior of tracheal cancers and explain disparities in survival.

\section{Conclusions}

This study suggests that women with primary tracheal tumors have significantly better survival than men, in both univariate and multivariate analysis. Since female sex is an independent prognostic factor for tracheal tumors, the ratio of women to men should be taken into consideration in reports comparing the outcomes of different treatments. The reasons why women with tracheal tumors live longer than men remain unexplained. Studies on genetic, hormonal, and metabolic factors could help explain sex-specific differences in survival rates.

\section{Conflict of interest: none declared}

\section{Aleksandra Piórek} \\ Maria Sklodowska-Curie National Research Institute of Oncology \\ Lung Cancer and Chest Tumor Department \\ ul. Roentgena 5 \\ 02-781 Warszawa, Poland \\ e-mail:aleksandra.piorek@pib-nio.pl
}

\section{Received: 29 Jun 2021}

Accepted: $26 \mathrm{Jul} 2021$

\section{References}

1. Junker K. Pathology of tracheal tumors. Thorac Surg Clin. 2014; 24(1): 7-11, doi: 10.1016/j.thorsurg.2013.09.008, indexed in Pubmed: 24295655.

2. Macchiarini P. Primary tracheal tumours. Lancet Oncol. 2006; 7(1):83-91, doi: 10.1016/S1470-2045(05)70541-6, indexed in Pubmed: 16389188.

3. Madariaga ML, Gaissert HA. Overview of malignant tracheal tumors. Ann Cardiothorac Surg. 2018; 7(2): 244-254, doi: 10.21037/ acs.2018.03.04, indexed in Pubmed: 29707502.

4. Webb BD, Walsh GL, Roberts DB, et al. Primary tracheal malignant neoplasms: the University of Texas MD Anderson Cancer Center experience. J Am Coll Surg. 2006; 202(2): 237-246, doi: 10.1016/j. jamcollsurg.2005.09.016, indexed in Pubmed: 16427548.

5. Mallick S, Benson R, Giridhar $P$, et al. Demography, patterns of care and survival outcomes in patients with malignant tumors of trachea: A systematic review and individual patient data analysis of 733 patients. Lung Cancer. 2019; 132: 87-93, doi: 10.1016/j.lungcan.2019.04.017, indexed in Pubmed: 31097099.

6. Albers E, Lawrie T, Harrell JH, et al. Tracheobronchial adenoid cystic carcinoma: a clinicopathologic study of 14 cases. Chest. 2004; 125(3): 1160-1165, doi: 10.1378/chest.125.3.1160, indexed in Pubmed: 15006985.

7. Honings J, Gaissert HA, Weinberg AC, et al. Prognostic value of pathologic characteristics and resection margins in tracheal adenoid cystic carcinoma. Eur J Cardiothorac Surg. 2010; 37(6): 1438-1444, doi: 10.1016/j.ejcts.2010.01.005, indexed in Pubmed: 20356756.

8. Gaissert HA, Grillo HC, Shadmehr MB, et al. Long-term survival after resection of primary adenoid cystic and squamous cell carcinoma of the trachea and carina. Ann Thorac Surg. 2004; 78(6): 1889-96; discussion 1896, doi: 10.1016/j.athoracsur.2004.05.064, indexed in Pubmed: 15560996.

9. Regnard JF, Fourquier P, Levasseur P. Results and prognostic factors in resections of primary tracheal tumors: a multicenter retrospective study. The French Society of Cardiovascular Surgery. J Thorac Cardiovasc Surg. 1996; 111(4): 808-13; discussion 813, doi: 10.1016/s00225223(96)70341-0, indexed in Pubmed: 8614141.

10. Wen J, Liu Di, Xu X, et al. Nomograms for predicting survival outcomes in patients with primary tracheal tumors: a large population-based analysis. Cancer Manag Res. 2018; 10: 6843-6856, doi: 10.2147/CMAR. S186546, indexed in Pubmed: 30588090.

11. Bhattacharyya N. Contemporary staging and prognosis for primary tracheal malignancies: a population-based analysis. Otolaryngol Head Neck Surg. 2004; 131(5): 639-642, doi: 10.1016/j.otohns.2004.05.018, indexed in Pubmed: 15523440.

12. Zhengjaiang $L$, Pingzhang $T$, Dechao $Z$, et al. Primary tracheal tumours: 21 years of experience at Peking Union Medical College, Beijing, China. J Laryngol Otol. 2008; 122(11): 1235-1240, doi: 10.1017/ S0022215108001710, indexed in Pubmed: 18331654.

13. Urdaneta Al, Yu JB, Wilson LD. Population based cancer registry analysis of primary tracheal carcinoma. Am J Clin Oncol. 2011; 34(1): 32-37, doi: 10.1097/COC.0b013e3181 cae8ab, indexed in Pubmed: 20087156.

14. Napieralska A, Miszczyk L, Blamek S. Tracheal cancer - treatment results, prognostic factors and incidence of other neoplasms. Radiol Oncol. 2016; 50(4): 409-417, doi: 10.1515/raon-2016-0046, indexed in Pubmed: 27904449.

15. Makarewicz R, Mross M. Radiation therapy alone in the treatment of tumours of the trachea. Lung Cancer. 1998; 20(3): 169-174, doi: 10.1016/ s0169-5002(98)00018-x, indexed in Pubmed: 9733051.

16. Hetnał M, Kielaszek-Ćmiel A, Wolanin M, et al. Tracheal cancer: Role of radiation therapy. Rep Pract Oncol Radiother. 2010; 15(5): 113-118, doi: 10.1016/j.rpor.2010.08.005, indexed in Pubmed: 24376936.

17. Honings J, van Dijck JA, Verhagen AdF, et al. Incidence and treatment of tracheal cancer: a nationwide study in the Netherlands. Ann Surg Oncol. 2007; 14(2): 968-976, doi: 10.1245/s10434-006-9229-z, indexed in Pubmed: 17139460.

18. Manninen MP, Pukander JS, Flander MK, et al. Treatment of primary tracheal carcinoma in Finland in 1967-1985. Acta Oncol. 1993; 32(3): 277-282, doi: 10.3109/02841869309093595, indexed in Pubmed: 8323765 .

19. Licht PB, Friis S, Pettersson G. Tracheal cancer in Denmark: a nationwide study. Eur J Cardiothorac Surg. 2001; 19(3): 339-345, doi: 10.1016/ s1010-7940(01)00597-8, indexed in Pubmed: 11251276.

20. Yang KY, Chen YM, Huang MH, et al. Revisit of primary malignant neoplasms of the trachea: clinical characteristics and survival analysis. Jpn J Clin Oncol. 1997; 27(5): 305-309, doi: 10.1093/jjco/27.5.305, indexed in Pubmed: 9390206.

21. Chao MW, Smith JG, Laidlaw C, et al. Results of treating primary tumors of the trachea with radiotherapy. Int J Radiat Oncol Biol Phys. 1998; 41(4): 779-785, doi: 10.1016/s0360-3016(98)00120-5, indexed in Pubmed: 9652838.

22. Jeremic B, Shibamoto $Y$, Acimovic $L$, et al. Radiotherapy for primary squamous cell carcinoma of the trachea. Radiother Oncol. 1996;41(2): 135-138, doi: 10.1016/s0167-8140(96)01797-5, indexed in Pubmed: 9004356.

23. Mornex F, Coquard R, Danhier $\mathrm{S}$, et al. Role of radiation therapy in the treatment of primary tracheal carcinoma. Int J Radiat Oncol Biol Phys. 1998; 41(2): 299-305, doi: 10.1016/s0360-3016(98)00073-x, indexed in Pubmed: 9607345.

24. Agulnik M, Cohen EWE, Cohen RB, et al. Phase II study of lapatinib in recurrent or metastatic epidermal growth factor receptor and/or erbB2 expressing adenoid cystic carcinoma and non adenoid cystic carcinoma malignant tumors of the salivary glands. J Clin Oncol. 2007; 25(25): 3978-3984, doi: 10.1200/JCO.2007.11.8612, indexed in Pubmed: 17761983.

25. Lee JH, Jung EJ, Jeon $\mathrm{K}$, et al. Treatment outcomes of patients with adenoid cystic carcinoma of the airway. Lung Cancer. 2011; 72(2): 244-249, doi: 10.1016/j.lungcan.2010.08.011, indexed in Pubmed: 20828861.

26. Molina JR, Aubry MC, Lewis JE, et al. Primary salivary gland-type lung cancer: spectrum of clinical presentation, histopathologic and prognostic factors. Cancer. 2007; 110(10): 2253-2259, doi: 10.1002/cncr.23048, indexed in Pubmed: 17918258. 
27. Afshar N, English DR, Blakely T, et al. Differences in cancer survival by sex: a population-based study using cancer registry data. Cancer Causes Control. 2018; 29(11): 1059-1069, doi: 10.1007/s10552-018-1079-z, indexed in Pubmed: 30194549.

28. Barquín M, Calvo V, García-García F, et al. Sex is a strong prognostic factor in stage IV non-small-cell lung cancer patients and should be considered in survival rate estimation. Cancer Epidemiol. 2020; 67: 101737, doi: 10.1016/j.canep.2020.101737, indexed in Pubmed: 32450544.

29. Hsu LH, Chu NM, Liu CC, et al. Sex-associated differences in non-small cell lung cancer in the new era: is gender an independent prognostic factor? Lung Cancer. 2009; 66(2): 262-267, doi: 10.1016/j. lungcan.2009.01.020, indexed in Pubmed: 19299032.

30. Ferguson $M$, Wang J, Hoffman $P$, et al. Sex-associated differences in survival of patients undergoing resection for lung cancer. Ann Thorac Surg. 2000; 69(1): 245-249, doi: 10.1016/s0003-4975(99)01078-4.

31. Minami $H$, Yoshimura $M$, Miyamoto $Y$, et al. Lung cancer in women: sex-associated differences in survival of patients undergoing resection for lung cancer. Chest. 2000; 118(6): 1603-1609, doi: 10.1378/ chest.118.6.1603, indexed in Pubmed: 11115446.

32. Radzikowska E, Głaz P, Roszkowski K. Lung cancer in women: age, smoking, histology, performance status, stage, initial treatment and survival. Population-based study of 20561 cases. Ann Oncol. 2002; 13(7): 10871093, doi: 10.1093/annonc/mdf187, indexed in Pubmed: 12176788.

33. Radzikowska E, Głaz P. [The role of sex as a prognostic factor in lung cancer]. Pneumonol Alergol Pol. 2000; 68(9-10): 425-433, indexed in Pubmed: 11276973

34. Ellington CL, Goodman M, Kono SA, et al. Adenoid cystic carcinoma of the head and neck: Incidence and survival trends based on 1973-2007 Surveillance, Epidemiology, and End Results data. Cancer. 2012; 118(18): 4444-4451, doi: 10.1002/cncr.27408, indexed in Pubmed: 22294420.

35. Yang H, Yao F, Tantai J, et al. Resected Tracheal Adenoid Cystic Carcinoma: Improvements in Outcome at a Single Institution. Ann Thorac Surg. 2016; 101(1): 294-300, doi: 10.1016/j.athoracsur.2015.06.073, indexed in Pubmed: 26431923.
36. Båtevik R, Grong K, Segadal L, et al. The female gender has a positive effect on survival independent of background life expectancy following surgical resection of primary non-small cell lung cancer: a study of absolute and relative survival over 15 years. Lung Cancer. 2005; 47(2): 173-181, doi: 10.1016/j.lungcan.2004.08.014, indexed in Pubmed: 15639716.

37. Wolf M, Holle R, Hans K, et al. Analysis of prognostic factors in 766 patients with small cell lung cancer (SCLC): the role of sex as a predictor for survival. Br J Cancer. 1991;63(6): 986-992, doi: 10.1038/bjc.1991.215, indexed in Pubmed: 1648949.

38. Asmis TR, Ding K, Seymour L, et al. National Cancer Institute of Canada Clinical Trials Group. Age and comorbidity as independent prognostic factors in the treatment of non small-cell lung cancer: a review of National Cancer Institute of Canada Clinical Trials Group trials. J Clin Oncol. 2008; 26(1): 54-59, doi: 10.1200/JCO.2007.12.8322, indexed in Pubmed: 18165640.

39. Wang $Y$, Hunt K, Nazareth I, et al. Do men consult less than women? An analysis of routinely collected UK general practice data. BMJ Open. 2013; 3(8): e003320, doi: 10.1136/bmjopen-2013-003320, indexed in Pubmed: 23959757.

40. Galdas PM, Cheater F, Marshall P. Men and health help-seeking behaviour: literature review. J Adv Nurs. 2005; 49(6): 616-623, doi: 10.1111/j.1365-2648.2004.03331.x, indexed in Pubmed: 15737222.

41. Hamidi M, Moody JS, Kozak KR. Refusal of radiation therapy and its associated impact on survival. Am J Clin Oncol. 2010; 33(6): 629-632, doi: 10.1097/COC.0b013e3181d270ce, indexed in Pubmed: 20216302.

42. Mok T, Wu YL, Thongprasert S, et al. Gefitinib or Carboplatin-Paclitaxel in Pulmonary Adenocarcinoma. N Engl J Med. 2009; 361(10): 947-957, doi: 10.1056/nejmoa0810699.

43. Radkiewicz C, Dickman PW, Johansson AL, et al. Sex and survival in non-small cell lung cancer: A nationwide cohort study. PLoS One. 2019; 14(6): e0219206, doi: 10.1371/journal.pone.0219206, indexed in Pubmed: 31247015. 